Gut, 1976, 17, 685-691

\title{
Exocrine pancreatic function in juvenile-onset diabetes mellitus
}

\author{
B. M. FRIER, J. H. B. SAUNDERS, K. G. WORMSLEY, AND \\ I. A. D. BOUCHIER
}

From the Division of Medicine, Ninewells Hospital and Medical School, University of Dundee, Dundee

SUMMARY Exocrine pancreatic function was studied in 20 juvenile-onset diabetics, seven maturityonset diabetics, and five patients with diabetes secondary to chronic pancreatitis. The results were compared with 13 non-diabetic controls. The outputs of bicarbonate, trypsin, and amylase were reduced in the diabetic patients in response to intravenous secretin and CCK-PZ. In the juvenileonset group, exocrine pancreatic secretory capacity was reduced in $80 \%$ of the patients, and the severity of the reduction was related to the duration of the diabetes. The reduction in pancreatic secretory capacity must be taken into consideration when interpreting pancreatic exocrine function in patients with diabetes.

Abnormal exocrine pancreatic function has been reported in patients with juvenile-onset and maturityonset diabetes mellitus (Jones et al., 1925; Diamond and Siegel, 1940; Pollard et al., 1943; Chey et al., 1963; Vacca et al., 1964; Bock et al., 1967; Drewes, 1969; Yamagata et al., 1969; Baron and Nabarro, 1973; Domschke et al., 1975). Neither the frequency nor the cause of the pancreatic dysfunction in the insulin-dependent diabetics has been fully defined.

In the present study the exocrine pancreatic secretory capacity of a group of juvenile-onset diabetics was investigated by measuring the pancreatic response to stimulation with an intravenous infusion of secretin and cholecystokinin-pancreozymin (CCK-PZ). The aims of the investigation were to establish the frequency of exocrine pancreatic dysfunction and to assess the relationship between the degree of impairment and the duration of the disease as well as the quality of diabetic control.

\section{Methods}

Twenty patients with insulin-dependent diabetes (Table 1) and seven patients with maturity-onset diabetes who did not require insulin were studied. Thirteen non-diabetic patients matched for age and sex, who were undergoing investigation for abdominal pain and who had no subsequent clinical, radiological, or functional evidence of pancreatic

Received for publication 17 June 1976 disease, were studied as controls. A group of five patients with diabetes secondary to confirmed chronic pancreatitis has also been included for comparison. Eight of the insulin-dependent diabetics had diabetes for less than five years, five had diabetes between five and 10 years, and seven had diabetes for more than $\mathbf{1 0}$ years. All patients gave informed consent to the study.

The quality of their diabetic control in the preceding 12 months was assessed using criteria similar to those used by Pirart et al. (1975) in their prospective study of diabetic control. Control is expressed as 'good', 'variable', or 'poor', using the criteria as shown (Table 2). Patients were studied within 12 hours of insulin administration and after an overnight fast. Care was taken to ensure that there was no evidence of ketoacidosis at the time of study and that the withdrawal of insulin had not produced hyperglycaemia before pancreatic stimulation. Plasma glucose was monitored, and the level at the time of pancreatic stimulation is shown (Table 1). With the exception of three patients (nos. 4, 9, and 15), the plasma glucose concentration was less than $16.6 \mathrm{mmol} / 1(300 \mathrm{mg} / 100 \mathrm{ml})$, and two of these patients (nos. 4 and 9) were restudied after receiving their normal pre-breakfast dose of insulin.

Intubation was performed with a multiple-lumen tube; the distal aspiration site was positioned under fluoroscopic control in the second part of the duodenum with the proximal aspiration site in the gastric antrum. Aspirates were collected from both sites by continuous mechanical suction in 15 minute 
Table 1 Clinical details of 20 insulin dependent patients

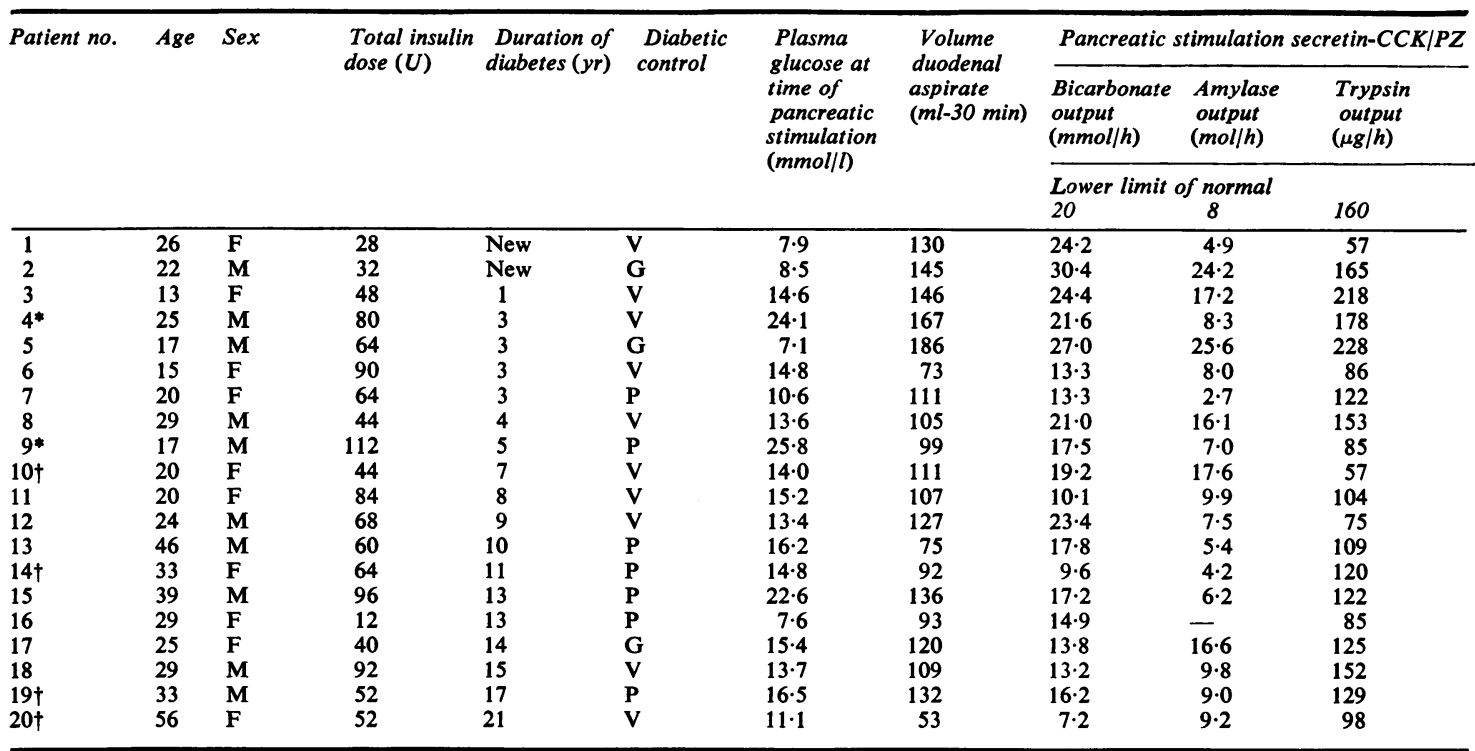

* Restudied after insulin administration. †Restudied using double hormone dose. V: variable. G: good. P: poor.

Table 2 Quality of diabetic control

\begin{tabular}{cl}
\hline Criteria & \\
Good & $\begin{array}{l}\text { No episodes of coma (ketoacidosis) and plasma glucose } \\
<11 \cdot 1 \mathrm{mmol} / 1(200 \mathrm{mg} / 100 \mathrm{ml}), \mathrm{two} \text { hours post-prandial }\end{array}$ \\
Variable & $\begin{array}{l}\text { One episode of hyperglycaemic coma and fluctuating } \\
\text { plasma glucose between } 11 \cdot 1 \text { and } 16.6 \mathrm{mmol} / \mathrm{l}(300 \\
\mathrm{mg} / 100 \mathrm{ml}), \text { two hours post-prandial }\end{array}$ \\
Poor & $\begin{array}{l}\text { More than one episode of hyperglycaemic coma, and } \\
\text { fluctuating plasma glucose, }>16.6 \mathrm{mmol} / \mathrm{l}, \text { two hours } \\
\text { post-prandial }\end{array}$
\end{tabular}

Assessment

12 months before pancreatic stimulation. A minimum number of six plasma glucose estimations (two hours post-prandial) were used to evaluate quality of control in each patient

batches. After a 15-minute basal collection, an intravenous infusion of secretin (1 Clinical Unit/ kg-h) and CCK-PZ (1 Ivy Unit/kg-h) in 0.15 mmol/1 sodium chloride was administered for 45 minutes. In four patients (nos. 10, 14, 19, and 20) double the dose of hormones $(2 \mathrm{CU} / \mathrm{kg}-\mathrm{h}$ secretin plus $2 \mathrm{IU} / \mathrm{kg}-\mathrm{h}$ CCK-PZ) were used to ensure that a maximal secretory response had been achieved. The hormones were obtained from the G.I.H. Laboratory, Karolinska Institute, Stockholm, Sweden. Bicarbonate concentration was measured by adding $1 \mathrm{ml}$ duodenal aspirate to $2 \mathrm{ml} 0.1 \mathrm{~mol} / 1$ hydrochloric acid, and titrating the excess acid after boiling to $\mathrm{pH} 7 \cdot 0$; trypsin was measured photometrically using N-alpha-Benzoyl-d-l-arginine-pnitroamilide hydrochloride as substrate, and amylase by the method of Bernfeld and Studer-Pecha (1947). Results are expressed as output per hour, by doubling the sum of the outputs during the steady state response of the final two 15-minute periods of hormonal stimulation. Faecal fat was measured by the modified Van der Kamer method for wet faeces (Anderson et al., 1952). The statistical significance of the differences in pancreatic outputs was assessed using the Mann-Whitney $U$ test.

\section{Results}

The outputs of bicarbonate, trypsin, and amylase of all the groups of diabetic patients were significantly reduced compared with the non-diabetic patients (Figs. 1-3). The bicarbonate outputs of the insulindependent patients with diabetes of more than 10 years' duration were significantly reduced when compared with those of less than five years' duration (P $<0.01$ ) (Fig. 1). The same tendency to reduction in output of trypsin and amylase was observed with increasing duration of the diabetes, but the differences between the insulin-dependent groups were not significant (Figs. 2 and 3). Overall, $80 \%$ of the insulin-dependent patients had abnormal outputs of trypsin, and $65 \%$ of amylase. However, the reduction in outputs compared with the mean values of the non-diabetic controls was greater for amylase $(66 \%)$ than for trypsin $(54 \%)$. The degree of exocrine pancreatic insufficiency demonstrated in the group of patients with chronic pancreatitis and secondary diabetes was much more severe than any of the other groups (Figs. 1 and 2). 

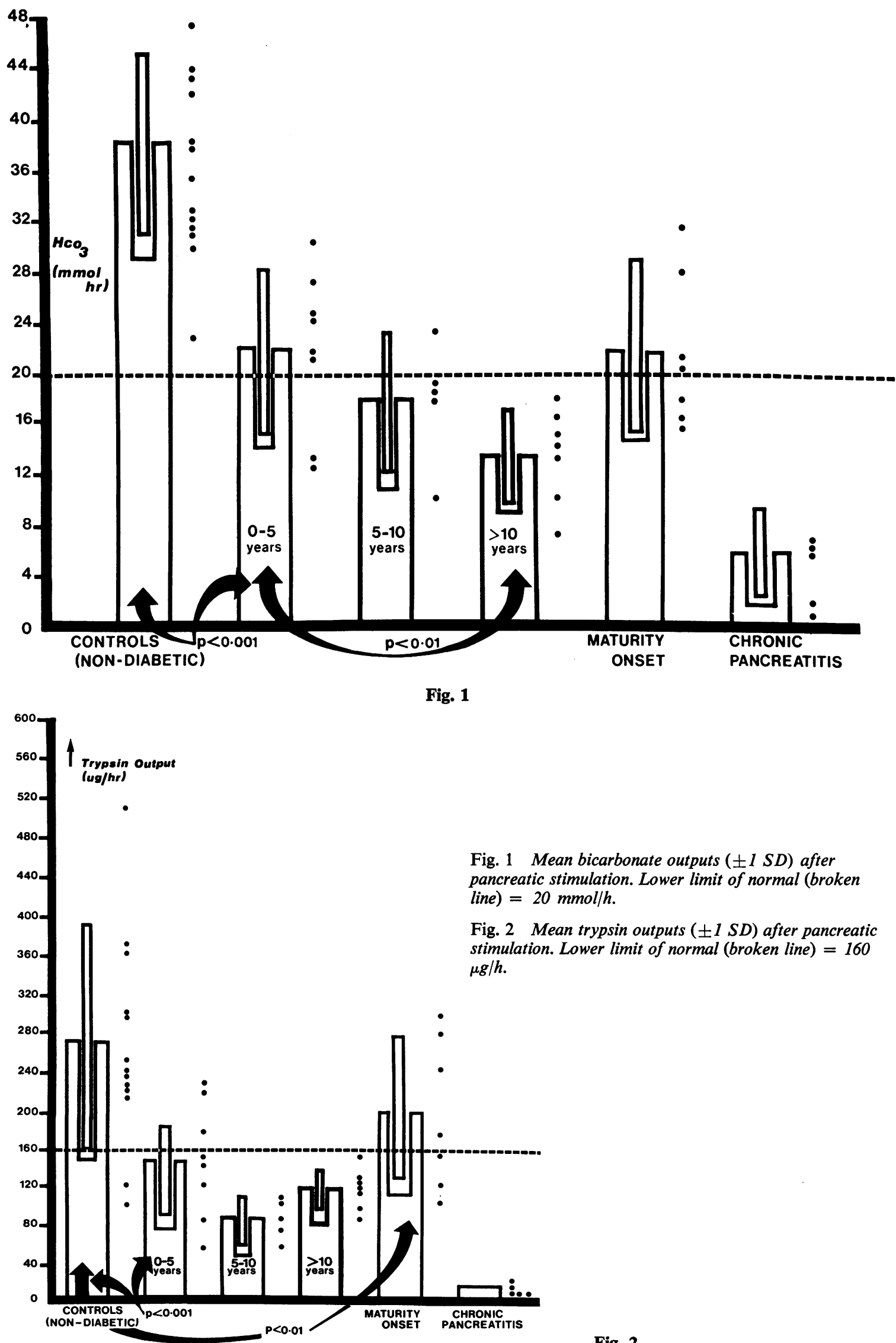

Fig. 2 


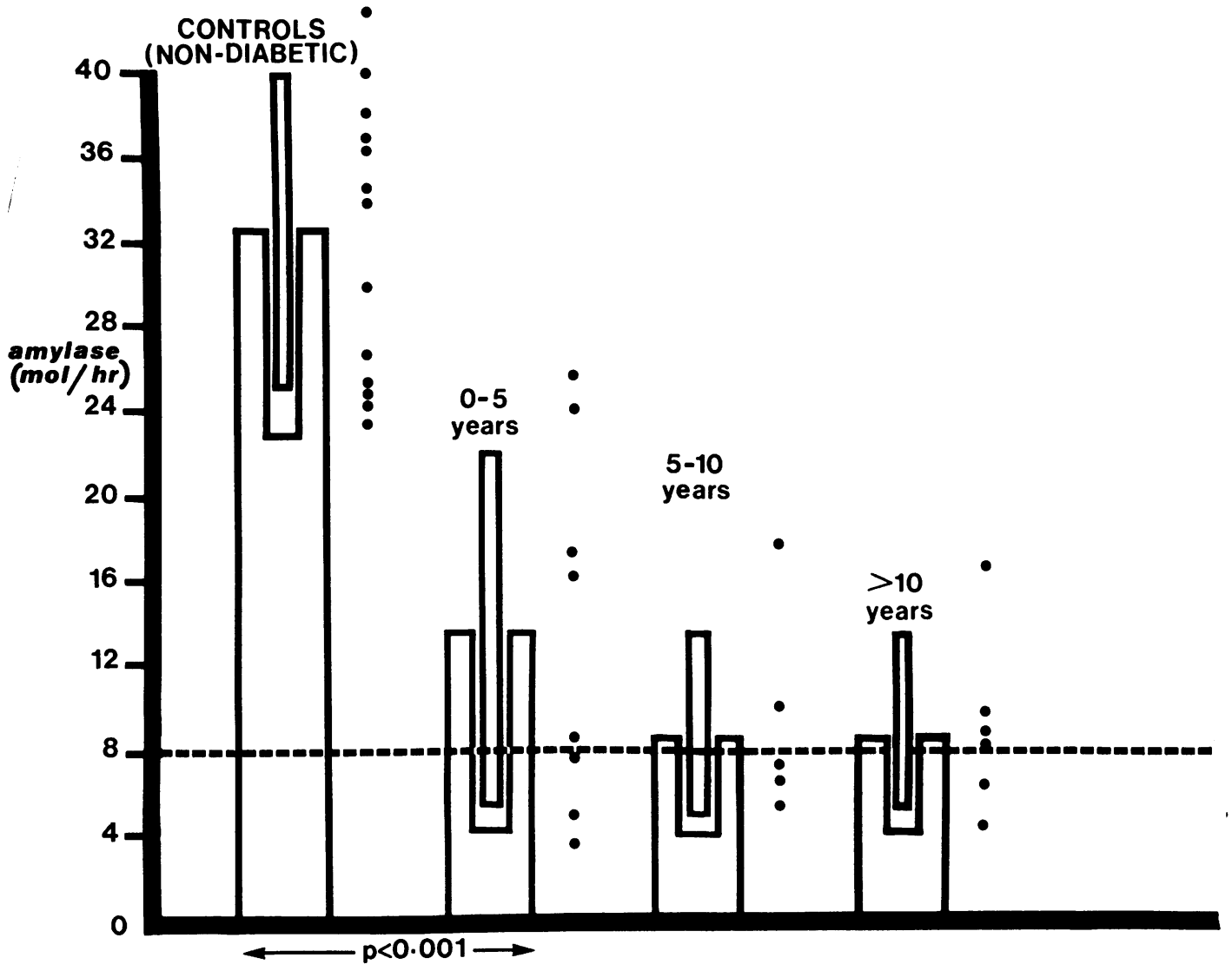

Fig. 3 Mean amylase outputs $( \pm 1 S D)$ after pancreatic stimulation. Lower limit of normal (broken line) $=$ $8 \mathrm{~mol} / \mathrm{h}$.

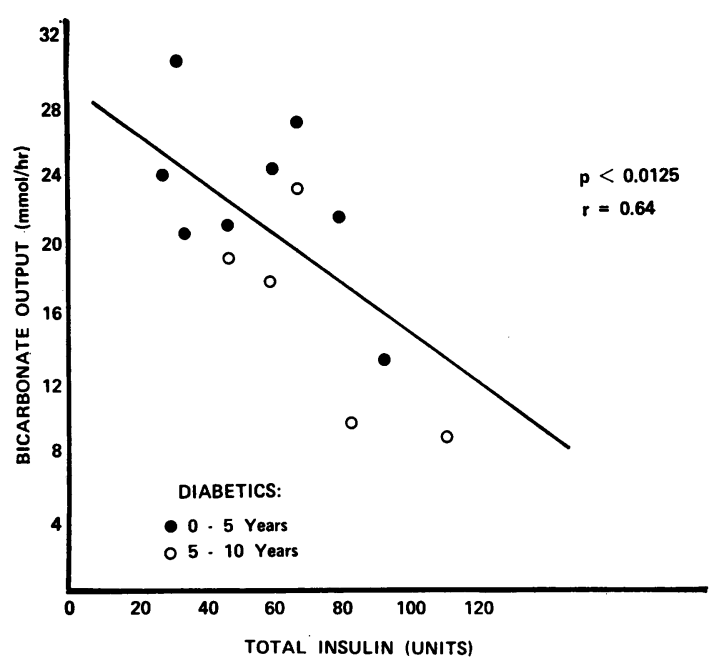

Fig. 4 Relationship between bicarbonate output and total daily insulin dose in juvenile-onset diabetics of less than 10 years' duration.
The outputs of bicarbonate of the insulindependent patients with diabetes of less than 10 years' duration showed a significant inverse relationship $(r=-0.64 ; \mathrm{P}<0.0125)$ with the total daily insulin dosage required for control of the diabetes (Fig. 4). No significant correlation was found between the more severely reduced bicarbonate response to the hormones in patients with diabetes greater than 10 years' duration, and their requirement of insulin. No significant correlation was found between insulin dosage and outputs of trypsin and amylase in diabetics of any duration, nor was there any significant correlation between exocrine pancreatic secretory capacity and the preceding quality of diabetic control as judged arbitrarily by the criteria shown.

The exocrine pancreatic response to double the dose of secretin and CCK-PZ did not differ significantly from the response to the standard dose of the hormones, indicating that the response elicited by the lower dose was maximal. Two of the diabetic patients (nos. 4 and 9) who had hyperglycaemia 
without ketoacidosis after insulin withdrawal, were restudied, having received their pre-breakfast insulin 60 minutes before pancreatic stimulation. Plasma glucose fell from 22.6 to $15.7 \mathrm{mmol} / \mathrm{l}$ (patient no. 4) and from 23.4 to $14.6 \mathrm{mmol} / \mathrm{l}$ (patient no. 9), with a concurrent decline in serum osmolality. The exocrine pancreatic response of both patients was unchanged.

\section{Discussion}

In the present study exocrine parcreatic secretory capacity was found to be reduced, compared with normal subjects, in $80 \%$ of insulin-dependent diabetics, and the degree of dysfunction increased with the duration of the disease. In previous reports the pancreatic dysfunction most frequently demonstrated has been an abnormally low output of amylase in up to $77 \%$ of patients (Pollard et al., 1943; Chey et al., 1963; Vacca et al., 1964; Bock et al., 1967; Drewes, 1969; Domschke et al., 1975). Low bicarbonate (Diamond and Siegel, 1940; Pollard et al., 1943; Chey et al., 1963; Vacca et al., 1964; Bock et al., 1967; Domschke et al., 1975), trypsin (Pollard et al., 1943; Domschke et al., 1975) and recently chymotrypsin (Domschke et al., 1975) outputs in response to pancreatic stimulants have also been described. In our study the output of amylase during stimulation with secretin and CCK-PZ was abnormal in $65 \%$ of patients, but the very high incidence and severity of the reduction in bicarbonate secretion was the most striking abnormality of exocrine pancreatic function in the insulindependent diabetic patients. All except one of the patients with diabetes of more than five years' duration had an abnormal bicarbonate-secretory response to the exogenous hormones. The incidence of low bicarbonate-secretory capacity is therefore much more common and severe than previously reported. The reduction of both bicarbonate and enzyme-secretory capacity in our patients with insulin-dependent diabetes was equivalent to the exocrine pancreatic dysfunction in non-diabetic patients with chronic pancreatitis (Wormsley, 1969). However, the reduction of exocrine secretory capacity in our diabetic patients was not so profound as in our patients in whom chronic pancreatitis was sufficiently severe also to cause endocrine pancreatic insufficiency. The difference in exocrine pancreatic function between patients suffering from chronic pancreatitis with diabetes, and those diabetic patients who show reduced exocrine pancreatic function is emphasised by the fact that our five patients with chronic pancreatitis all had severe steatorrhoea, indicating destruction of more than $90 \%$ of exocrine secretory capacity (Sarles $e t$ al., 1963; Di Magno et al., 1973). Our diabetic patients with exocrine pancreatic dysfunction all had a normal faecal fat content.

Our finding of a relationship between the duration of the diabetes and the severity of the exocrine pancreatic dysfunction conflicts with previous reports. For example, Chey et al. (1963) reported no apparent relationship between exocrine pancreatic dysfunction and the duration or the severity of the diabetes. Vacca et al. (1964) have suggested that the frequency of exocrine pancreatic abnormality is related not to the duration of the disease, but to the age of the diabetic patients, although studies of exocrine pancreatic function in non-diabetic patients have shown no deterioration in function with age (Rosenberg et al., 1966; Delachaume-Salem and Sarles, 1970). Other studies have also failed to show any relationship between exocrine pancreatic dysfunction and the duration of the diabetes (Yamagata et al., 1969; Domschke et al., 1975), except that Drewes (1969) found less severe exocrine pancreatic dysfunction in newly diagnosed juvenile-onset diabetics than in diabetics with disease for many years.

Our objective assessment of the quality of diabetic control, for comparison with exocrine pancreatic secretion has been only qualitative and approximate because indices of control such as plasma glucose, or the degree of glycosuria monitored during hospital admission or at outpatient clinic attendance are not necessarily representative of the overall quality of control, or of the metabolic state which exists at the time of study. Our results suggest that the juvenile-onset diabetic patients with less than 10 years' history and 'good' control, have a better exocrine pancreatic secretory response to stimulation than less well-controlled patients with diabetes of similar duration.

The cause of the exocrine pancreatic dysfunction in diabetes mellitus is not known. The pancreas in juvenile-onset diabetes is sometimes atrophic and infiltrated with fat (Warren and Le Compte, 1966), and inflammatory infiltrates have been observed in and around the islets in the early stages of juvenileonset diabetes (Gepts, 1965). It has been suggested that repeated episodes of infarction with subsequent fibrosis may produce progressive destruction of the islets and acinar tissue, though evidence for this is limited (Blumenthal et al., 1963). It seems possible, therefore, that the exocrine dysfunction is related at least in part to progressive structural damage of the diabetic pancreas.

It has been proposed that exocrine pancreatic dysfunction in diabetic rats is caused by the lack of the trophic effect of insulin on acinar cells, particularly those surrounding the islets (Hansson, 1959). 
Studies in rats suggest that insulin is of particular importance for the synthesis and secretion of pancreatic amylase (Palla et al., 1968), but the effects of insulin deficiency on acinar cell function are complex and it is not clear if acinar cell damage is a direct result of insulin deficiency (Bruchhausen, 1975). Moreover, no effect of diabetes on the bicarbonate-secretory capacity of the pancreas has been reported in these animals.

The persistently raised circulating serum concentrations of glucagon in diabetes (Unger et al., 1970) may also have some functional effects on exocrine pancreatic secretion, because the injection of glucagon during pancreatic stimulation in nondiabetic subjects partially inhibited the secretion of enzymes, although bicarbonate secretion was unaffected (Zajtchuk et al., 1967; Dyck et al., 1970). The influence of persistently raised serum concentrations of glucagon on exocrine pancreatic function is not known, but is undergoing further study in our patients.

As the patients had not received insulin from the day before each test, we considered the possibility that the relative lack of metabolic control of our diabetic patients during the test procedure might have contributed to the abnormal exocrine secretory responses that were found, because variations in the osmolality of perfusate had been shown to affect exocrine pancreatic secretion at least in the isolated cat pancreas (Case et al., 1968). In patients with reasonable diabetic control at the time of study, the variation in serum osmolality is unlikely significantly to influence exocrine pancreatic secretion, as the contribution of glucose to serum osmolality is relatively small at plasma glucose concentrations below $16.6 \mathrm{mmol} / \mathrm{l}$. In any case, the administration of insulin shortly before pancreatic stimulation had been shown to make no appreciable difference to the exocrine response (Domschke et al., 1975), and we confirmed this finding in two patients.

Although the cause has not yet been defined, we conclude that exocrine pancreatic dysfunction in insulin-dependent diabetics is a real and significant feature of the disease, and must be taken into account when attempting assessment of exocrine pancreatic function in patients with diabetes.

We wish to thank Miss S. Drummond, Mrs F. Dear, and Dr G. Masoero for technical assistance, and Dr J. D. Baird for helpful criticism.

\section{References}

Anderson, C. M., Frazer, A. C., French, J. M., Gerrard, J. W., Sammons, H. G., and Smellie, J. M. (1952). Coeliac disease: gastro-intestinal studies and the effect of dietary wheat flour. Lancet, 1, 836-842.

Baron, J. H., and Nabarro, J. D. N. (1973). Pancreatic exocrine function in maturity onset diabetes mellitus. British Medical Journal, 4, 25-27.

Bernfeld, P., and Studer-Pecha, H. (1947). Sur les enzymes amylolytiques 2 . L'affinité entre enzyme et substratum pour quelques a-amylases. Helvetica Chimica Acta, 30, 1904-1910.

Blumenthal, H. T., Probstein, J. G., and Berns, A. W. (1963). Interrelationship of diabetes mellitus and pancreatitis. Archives of Surgery, 87, 844-850.

Bock, O. A. A., Bank, S., Marks, I. N., and Jackson, W. P. U. (1967). Exocrine pancreatic function in diabetes mellitus. South African Medical Journal, 41, 756-758.

Bruchhausen, F. von (1975). Insulin II, p. 545. Edited by A. Hasselblatt and F. von Bruchhausen. Springer: Berlin.

Case, R. M., Harper, A. A., and Scratcherd, T. (1968). Water and electrolyte secretion by the perfused pancreas of the cat. Journal of Physiology, 196, 133-149.

Chey, W. Y., Shay, H., and Shuman, C. R. (1963). External pancreatic secretion in diabetes mellitus. Annals of Internal Medicine, 59, 812-821.

Delachaume-Salem, E., and Sarles, H. (1970). Normal human pancreatic secretion in relation to age. Biologie et Gastroenterologie, 2, 135-146.

Diamond, J. S., and Siegel, S. A. (1940). The secretin test in the diagnosis of pancreatic disease with a report of 130 tests. American Journal of Digestive Diseases, 7, 435 442.

Di Magno, E. P., Go, V. L. W., and Summerskill, W. H. J. (1973). Relations between pancreatic enzyme outputs and malabsorption in severe pancreatic insufficiency. New England Journal of Medicine, 288, 813-815.

Domschke, W., Tympner, F., Domschke, S., and Demling, L. (1975). Exocrine pancreatic function in juvenile diabetics. American Journal of Digestive Diseases, 20, 309-312.

Drewes, V. M. (1969). Exocrine pancreatic function estimated after intraduodenal and after oral stimulation, and exocrine pancreatic function in patients with newly discovered diabetes mellitus and in long-term diabetes. In Modern Gastroenterology, pp. 1229-1231. Edited by 0. Gregor and O. Riedl. Schattauer: Stuttgart.

Dyck, W. P., Texter, E. C., Jr, Lasater, J. M., and Hightower, N. C., Jr. (1970). Influence of glucagon on pancreatic exocrine secretion in man. Gastroenterology, 58, 532-539.

Gepts, W. (1965). Pathologic anatomy of the pancreas in juvenile diabetes mellitus. Diabetes, 14, 619-633.

Hansson, E. (1959). The formation of pancreatic juice proteins studied with labelled amino acids. Acta Physiologica Scandinavica, 46, Suppl. 161, 1-99.

Jones, C. M., Castle, W. B., Mulholland, H. B., and Bailey, F. (1925). Pancreatic and hepatic activity in diabetes mellitus. Archives of Internal Medicine, 35, 315-336.

Palla, J. C., Abdeljlil, A.ben, and Desneulle, P. (1968). Effect of insulin on the rate of biosynthesis of some pancreatic enzymes. Gut, 9, 254. (Abstract.)

Pirart, J., Lauvaux, J. P., and Eisendrath, C. (1975). Diabetic retinopathy, nephropathy, neuropathy: relation to duration and control. A statistical study in 4,400 diabetics. 11 th Meeting of the European Association for the Study of Diabetes, Munich. Diabetologia, 11, 370. (Abstract.)

Pollard, H. M., Miller, L., and Brewer, W. A. (1943). The external secretion of the pancreas and diabetes mellitus. American Journal of Digestive Diseases, 10, 20-23.

Rosenberg, I. R., Friedland, N., Janowitz, H. D., and Dreiling, D. A. (1966). The effect of age and sex upon human pancreatic secretion of fluid and bicarbonate. Gastroenterology, 50, 191-194.

Sarles, H., Pastor, J., Pauli, A. M., and Barthelemy, M. 
(1963). Determination of pancreatic function. A statistical analysis conducted in normal subjects and in patients with proven chronic pancreatitis. Gastroenterologia (Basel), 99, 279-300.

Unger, R. H., Aguilar-Parada, E., Müller, W. A., and Eisentraut, A. M. (1970). Studies of pancreatic alpha cell function in normal and diabetic subjects. Journal of Clinical Investigation, 49, 837-848.

Vacca, J. B., Henke, W. J., and Knight, W. A., Jr. (1964). The exocrine pancreas in diabetes mellitus. Annals of Internal Medicine, 61, 242-247.

Warren, S., Le Compte, P. M. and Legg, M. A. (1966). The Pathology of Diabetes Mellitus, pp. 102-115, and 351363. Kimpton: London.
Wormsley, K. G. (1969). The response to infusion of a combination of secretin and pancreozymin in health and disease. Scadinavian Journal of Gastroenterology, 4, 623-632.

Yamagata, S., Goto, Y., Takebe, T., and Koizumi, H (1969). Exocrine and endocrine function of the pancreas in diabetes mellitus and chronic pancreatitis. In Modern Gastroenterology, pp. 1298-1300. Schattauer: Stuttgart.

Zajtchuk, R., Amato, J. J., Paloyan, E., and Baker, R. J. (1967). Inhibition of pancreatic exocrine secretion by glucagon. Surgical Forum, 18, 410-411.

Address for reprints: I.A.D.B., Division of Medicine, Ninewells Hospital and Medical School, Dundee, DD1 9SY, Scotland. 